\title{
Primary care patient and provider preferences for diabetes care managers
}

\author{
This article was published in the following Dove Press journal: \\ Patient Preference and Adherence \\ 17 June 2010 \\ Number of times this article has been viewed
}

\author{
Ramona S Dejesus' \\ Kristin S Vickers ${ }^{2}$ \\ Robert J Stroebel' \\ Stephen S Cha ${ }^{3}$ \\ 'Division of Primary Care Internal \\ Medicine, Mayo Clinic, Rochester, MN, \\ USA; ${ }^{2}$ Department of Psychiatry and \\ Psychology, Mayo Clinic, MN, USA; \\ ${ }^{3}$ Department of Biostatistics, Mayo \\ Clinic, Rochester, MN, USA
}

Purpose: The collaborative care model, using care managers, has been shown to be effective in achieving sustained treatment outcomes in chronic disease management. Little effort has been made to find out patient preferences for chronic disease care, hence, we conducted a study aimed at identifying these.

Methods: A 20-item questionnaire, asking for patients' and providers' preferences and perceptions, was mailed out to 1000 randomly selected patients in Olmsted County, Minnesota, identified through a diabetes registry to have type 2 diabetes mellitus, a prototypical prevalent chronic disease. Surveys were also sent to 42 primary care providers.

Results: There were $254(25.4 \%)$ patient responders and $28(66 \%)$ provider responders. The majority of patients $(>70 \%)$ and providers $(89 \%)$ expressed willingness to have various aspects of diabetes care managed by a care manager. Although $75 \%$ of providers would be comfortable expanding the care manager role to other chronic diseases, only $39.5 \%$ of patient responders would be willing to see a care manager for other chronic problems. Longer length of time from initial diagnosis of diabetes was associated with decreased patient likelihood to work with a care manager.

Conclusion: Despite study limitations, such as the lack of validated measures to assess perceptions related to care management, our results suggest that patients and providers are willing to collaborate with a care manager and that both groups have similar role expectations of a care manager.

Keywords: care manager, collaborative care, patient preference, diabetes care

\section{Introduction}

The increasing challenges of responding to chronic disease management and prevention have particularly impacted the primary care setting, where the acute care model has long been in place. A major rethinking of practice models focusing on chronic disease management has occurred. The collaborative care model, using allied health staff such as nurses to act as care managers, has been consistently shown in studies to be effective in achieving sustained treatment outcomes in chronic disease management. ${ }^{1-3}$ In this model, a care manager plays a prominent role in implementing its key aspects; such as patient education towards self-management, coordination of tests, results notification, treatment plan discussions based on treatment guidelines, protocol-based regulation of medications, and maintenance of appropriate follow-ups at appropriate intervals for monitoring status and progress. ${ }^{3,4}$ The primary care physician maintains ownership of the patient, with the care manager providing support. However, patient participation in their chronic disease management that involves allied health practitioners has
Correspondence: Ramona S Dejesus Division of Primary Care Internal Medicine, Mayo Clinic, 200 First Street SW, Rochester, MN 55905, USA

Tel +l 5072840805

Fax + I 5072660036

Email dejesus.ramona@mayo.edu 
been challenging. This was shown by low patient enrollment in a recently reported study that randomized patients with diabetes and hypertension to nurse led education vs usual care. ${ }^{5}$ One assumption to low patient engagement in the model was familiarity with an acute care model, particularly among the elderly population, most of whom had been used to seeing their primary care physician for management of chronic problems. Only a few studies have addressed factors affecting patient participation in chronic disease care models. Patients' perceived barriers identified include poor physician communication, financial problems, and skepticism about nurses' professional background and training. ${ }^{6,7}$ Patient frailty and attitudinal and operational issues have been also cited. ${ }^{8}$ Provider-related barriers have likewise been encountered in the transition from acute to chronic disease practice models, including competing priorities and little engagement of physicians. $^{9}$

Little effort has been made to find out patient preferences regarding their chronic disease care within a collaborative model, as well as their role expectations for a non-physician care manager. Likewise, provider input has not traditionally been sought. Patients will generally accept a new care delivery model, so long as it does not preclude human contact or isolate them from their physicians and if it is endorsed by their physician. ${ }^{10}$

If we are to adapt a provider endorsed, patient-centered chronic disease management model, using nurse care managers in primary care, to enhance patient participation in such a model, and minimize potential barriers, there is a need to determine patient and provider perspectives on the role of a care manager and the factors that would make them willing participants in the model. We therefore conducted a survey aimed at identifying patient and provider preferences on how various aspects of a collaborative care model using care managers should be implemented. As a prototypical chronic disease of high prevalence, ${ }^{11}$ we chose to conduct this study among diabetic patients, utilizing a diabetes registry to identify those with type 2 diabetes mellitus.

\section{Methods}

A two-part questionnaire was sent to 1000 randomly selected community dwelling patients seen in the primary care clinic of a large academic institution in Midwest United States, identified through the registry to have type 2 diabetes mellitus. Patients residing in skilled care facilities were excluded. A cover letter, with a consent form describing the model, accompanied the survey questionnaire. Part 1, a 20-item questionnaire, consisted mostly of Likert scale type questions and 3 open-ended questions. Preference surveys have conventionally utilized Likert scale questions. ${ }^{12}$ A recently conducted survey by another division within the institution that already uses care managers, made use of Likert scale questions to ask patients' opinions on their experience with a care manager. Several of the questions in the present study instrument were adopted from that survey. The second part of the questionnaire focused on patient characteristics. The questionnaires were sent out and collected by the institution's survey center. A copy of the questionnaire is available upon request from the author. A second mailing was not done based on low response rates to such mailings in prior survey studies conducted within the institution.

All 42 primary care staff providers were invited to complete an abbreviated version of the survey, which included demographics and 10 questions from the 20-item questionnaire.

\section{Statistical analysis}

Descriptive statistics: frequency (\%) for categorical variables; or mean plus or minus standard deviation (mean $\pm \mathrm{SD}$ ) for continuous variables, were used to tabulate patient characteristics and data from patients' or staffs' close-ended questions, including Likert scale responses. Responses to open-ended questions were analyzed separately using qualitative methods and results will be reported separately.

Univariate Pearson Chi-square tests and multivariate logistic regression analyses; based on age, gender, years of diabetes diagnosis ( $\leq 5$ years; $\geq 6$ years), race, marital status, and years in school (grades 1-12; college/graduate/ postgraduate) were performed to determine if any of these variables significantly affected patients' responses regarding various aspects of the care manager role.

\section{Results \\ Demographics}

There were 254 (25\%) patient responders and 28 (66\%) provider responders. Patient demographic characteristics are reported in Table 1. Fifty-three percent of the patient responders were female, with $90 \%$ being 51 years or older. The majority (65\%) were married; 94\% were Caucasian; and 57\% had a college or higher education. One hundred and fifty-seven patients had been diagnosed with diabetes for over 5 years. More than half (61\%) had hypertension as a co-existing chronic disease and depression was present in $22 \%$ of responders. Among the primary care providers, $16(59.26 \%)$ were male, with 20 (74\%) being 41 years or older. Most (67\%) had been in practice for more than 10 years.

Tables $2 \mathrm{a}$ and $2 \mathrm{~b}$ summarize patient and provider responses on the care manager's role. 
Table I Patient demographics $(\mathrm{n}=254)$

\begin{tabular}{|c|c|c|}
\hline Characteristic & Number & $\%$ \\
\hline \multicolumn{3}{|l|}{ Age $(n=25 I)$} \\
\hline$\leq 50$ & 24 & $10 \%$ \\
\hline $5 I-70$ & 108 & $43 \%$ \\
\hline $71+$ & 119 & $47 \%$ \\
\hline \multicolumn{3}{|l|}{ Gender (n = 249) } \\
\hline Male & 116 & $47 \%$ \\
\hline Female & 133 & $53 \%$ \\
\hline \multicolumn{3}{|l|}{ Marital status $(n=249)$} \\
\hline Single/Divorced/Separated/Widowed & 86 & $35 \%$ \\
\hline Married & 163 & $65 \%$ \\
\hline \multicolumn{3}{|l|}{ Race $(n=25 I)$} \\
\hline White & 235 & $94 \%$ \\
\hline African American & 5 & $2 \%$ \\
\hline American Indian & $\mathrm{I}$ & $0 \%$ \\
\hline Asian & 3 & $1 \%$ \\
\hline Hispanic (Latino) & 4 & $2 \%$ \\
\hline Other & 3 & $1 \%$ \\
\hline \multicolumn{3}{|l|}{ Years of school finished $(n=246)$} \\
\hline Grades I-8 & 16 & $7 \%$ \\
\hline Grades 9-12 & 88 & $36 \%$ \\
\hline College/university (13-17) & 108 & $44 \%$ \\
\hline Graduate school (I8-22) & 22 & $9 \%$ \\
\hline Postgraduate $(23+)$ & 11 & $4 \%$ \\
\hline Multiple responses & 1 & $0 \%$ \\
\hline \multirow{2}{*}{\multicolumn{3}{|c|}{$\begin{array}{l}\text { Years since first diagnosed } \\
\text { with diabetes }(n=247)\end{array}$}} \\
\hline & & \\
\hline$\leq 5$ & 90 & $36 \%$ \\
\hline $6-10$ & 68 & $28 \%$ \\
\hline$\geq 11$ & 89 & $36 \%$ \\
\hline \multicolumn{3}{|l|}{ Means of getting to clinic } \\
\hline \multicolumn{3}{|l|}{ appointments $(n=250)$} \\
\hline Drive myself & 161 & $64 \%$ \\
\hline Take public transportation & 8 & $3 \%$ \\
\hline Family member & 28 & $11 \%$ \\
\hline Walk & 10 & $4 \%$ \\
\hline Other & 10 & $4 \%$ \\
\hline Multiple responses (9) & 33 & $13 \%$ \\
\hline
\end{tabular}

\section{Patient preferences and role expectations}

The majority of patients $(>70 \%)$ were willing to have various aspects of their diabetes care managed by a care manager. Most would also be comfortable discussing their health concerns with the care manager. Role expectations for a care manager were not statistically different among patients in sub-group univariate analysis based on: years from diagnosis of diabetes ( $\leq 5$ years; $\geq 6$ years); race; age; gender; marital status; and level of education. However, in multivariate analysis, those responders who had been diagnosed with diabetes for 11 or more years $(n=89)$ were less likely to see a care manager for a diabetes visit (OR: 0.551 ; CI: $0.315-0.965 ; P=0.037$ ), and were less confident that a care manager could help keep their diabetes under control (OR: 0.518; CI: 0.289-0.925; $P=0.026$ ). Interestingly, those diagnosed with diabetes for between 5 and 10 years were more willing to have a care manager schedule follow-up appointments for them and to discuss health concerns with them (Table 3). To ensure that results were not being skewed by the small percentage of responders who were less than 50 years and non-Caucasian, a separate multivariate analysis was performed excluding these two groups; there was no difference in results.

Sixty-two percent of responders had no gender preference for a diabetes care manager. As to qualification, $40 \%$ $(\mathrm{n}=101)$ preferred the care manager to be a Registered Nurse (RN) or Nurse Practitioner (NP) while $35 \%$ had no preference. More female patients would prefer a female care manager compared to male patients ( $53 \%$ vs $4 \%$; $P<0.001$ ). Only $40 \%$ of responders would be willing to see a care manager for other chronic illnesses and $37 \%$ were unsure. Almost two thirds $(n=180)$ had no prior experience of working with a care manager. Those who had been diagnosed with diabetes for 6 or more years had more prior experience with a care manager than those who had been diagnosed for 5 years or less ( $32 \%$ vs $15 \%$ ). When asked to choose what factor would keep them from using the services of a care manager, $38 \%$ indicated "cost"; another $35 \%$ indicated "don't know person enough" or "don't like change in care"; and 30\% had other reasons.

Table 2a Patients' preferences on care management by care managers (number $(\%)$; $\mathrm{n}=254$ )

\begin{tabular}{|c|c|c|c|c|}
\hline & Yes & Maybe & No & No answer \\
\hline Are you willing to see a care manager for diabetes visit? & $178(70.4 \%)$ & 49 (19.4\%) & $23(9.1 \%)$ & $3(1.2 \%)$ \\
\hline $\begin{array}{l}\text { Are you willing to have your treatment plan modified } \\
\text { by the care manager under the guidance of your doctor? }\end{array}$ & I 79 (70.8\%) & $43(17.0 \%)$ & $24(9.5 \%)$ & $7(2.8 \%)$ \\
\hline $\begin{array}{l}\text { Are you willing to have your tests scheduled } \\
\text { and coordinated by a care manager? }\end{array}$ & 190 (75.1\%) & 37 (14.6\%) & $21(8.3 \%)$ & $5(2.0 \%)$ \\
\hline $\begin{array}{l}\text { Are you willing to have the care manager contact you } \\
\text { to follow-up on your treatment progress? }\end{array}$ & 195 (77.1\%) & 31 (12.3\%) & $19(7.5 \%)$ & $8(3.2 \%)$ \\
\hline $\begin{array}{l}\text { Are you willing to have the care manager schedule } \\
\text { follow-up visits? }\end{array}$ & I9I (75.5\%) & 35 (I3.8\%) & $20(7.9 \%)$ & 7 (2.8\%) \\
\hline
\end{tabular}


Table 2b Providers' preferences on care management by care managers (number $(\%) ; n=28$ )

\begin{tabular}{|c|c|c|c|}
\hline & Yes & Maybe & No \\
\hline I am willing to have my patients with diabetes see a care manager & $26(92.9 \%)$ & I (3.6\%) & I (3.6\%) \\
\hline $\begin{array}{l}\text { I am willing to have my patient's treatment plan modified by the care manager } \\
\text { under my guidance or established protocol }\end{array}$ & $25(89.3 \%)$ & $2(7.1 \%)$ & I (3.6\%) \\
\hline $\begin{array}{l}\text { I am willing to have my patients' diabetes tests scheduled and coordinated } \\
\text { by a care manager }\end{array}$ & $27(96.4 \%)$ & I (3.6\%) & 0 \\
\hline $\begin{array}{l}\text { I am willing to have the care manager contact my patients to follow-up } \\
\text { on treatment progress }\end{array}$ & $27(96.4 \%)$ & I (3.6\%) & 0 \\
\hline $\begin{array}{l}\text { I am willing to have the care manager schedule follow-up clinic visits for } \\
\text { my patients if needed to ensure good control of their diabetes }\end{array}$ & $26(96.3 \%)$ & I (3.6\%) & 0 \\
\hline
\end{tabular}

As care managers would be coordinating most of patient's health education and follow-ups, responders were asked their preferences with respect to various aspects of their health care. On "test results notification", 130 patients $(51 \%)$ would prefer results to be communicated to them by letter or phone; $19 \%(n=47)$ would prefer being notified in person. The preference for letter and face-to-face notification of test results was higher among older patients ( $\geq 71$ years). Given a choice, only $11 \%$ of responders would prefer receiving diabetes education through a group class; $41 \%$ favored individual sessions.

\section{Provider preferences and role expectations}

At least $89 \%$ of providers were willing to have various aspects of their patients' diabetes care managed by a care manager. Over half of responders $(57 \%)$ were "somewhat" or "very confident" that a care manager could help their patients become activated in their diabetes care. Likewise, $89 \%$ would be "somewhat" or "extremely comfortable" discussing management plans for their patients with a care manager. In contrast to patient responders, $75 \%$ of providers were comfortable to expand the role of the care manager to other chronic diseases.

In univariate analyses using Pearson Chi-square, providers did not significantly differ in their responses on care manager roles when age or years of practice were factored in.

\section{Self-management characteristics}

Self-management is a key component of a chronic disease care model. Hence, the study investigators were particularly interested in identifying behavior patterns that may serve as predictors for patient engagement to the model and to selfmanagement, an essential component of the model. Certain questions were designed to capture this data based on review of available literature. ${ }^{13,14}$ When asked the question "Are you the person responsible for your health?", 244 (96\%) surprisingly answered "no". However, over $93 \%$ of patients indicated "self" to the question "Who looks after your diabetes?" Subjects were asked two questions that reflect self-activation behavior. The majority (60\%) responded "rarely" when asked how often they would call a nurse or nurse help line with a health question. Only 4\% answered "frequently". To the question "How often do you call your doctor's office to ask about test results if you have not heard anything back?", 211 patients (83\%) stated either "never", "rarely", or "occasionally".

Physical and cognitive capacities as well as health literacy have been identified as barriers to patient's self management behaviors. ${ }^{15}$ A single question, "How confident are you filling out medical forms by yourself?" has been shown to accurately screen limited health literacy. ${ }^{16}$ Over $70 \%$ of study participants responded "quite a bit" to "extremely" in relation to confidence with filling out medical forms themselves. Physically, most of the subjects appeared to be adequately mobile, as $65 \%$ were able to drive themselves or take public transportation to get to their clinic appointment.

\section{Discussion}

Both patients and providers expressed willingness to have various aspects of diabetes care managed by a care manager. While more than $75 \%$ of patients would be willing to have the care manager coordinate their care, slightly fewer patients (70\%) would be willing to have the care manager modify their treatment plan even with the provider's guidance. The latter is usually accomplished during clinic visits and may reflect patients' preference to maintain a certain degree of personal provider contact. It is interesting to note that length of time from initial diagnosis of diabetes is an independent variable affecting patients' perception of the care manager's role. Those diagnosed with the disease for 11 or more years appear to be less likely to use a care manager and less confident of a care manager's ability to help with diabetes care. This observation is not explained just by age. Although comprising less than a third of the responders, this sub-group of patients appeared to be less receptive to a new care model. It may therefore be crucial to adopt measures that would increase 
Table 3 Questions with significant responses on multivariate regression analysis $(n=249)$

\begin{tabular}{|c|c|c|c|c|}
\hline & \multirow{2}{*}{$\begin{array}{l}\text { Odds } \\
\text { ratio }\end{array}$} & \multicolumn{2}{|l|}{$95 \% \mathrm{Cl}$} & \multirow[t]{2}{*}{ P-value } \\
\hline & & Lower & Upper & \\
\hline \multicolumn{5}{|c|}{ I. Are you willing to see a care manager for a diabetes visit? } \\
\hline Male & 1.271 & 0.688 & 2.347 & 0.4436 \\
\hline Age $\leq 50$ & 1.647 & 0.553 & 4.910 & 0.3705 \\
\hline Age $\geq 71$ & 1.146 & 0.629 & 2.089 & 0.6566 \\
\hline Married & 1.446 & 0.781 & 2.678 & 0.2402 \\
\hline College education & 1.311 & 0.714 & 2.410 & 0.3825 \\
\hline Graduate school education & 1.560 & 0.592 & 4.111 & 0.3685 \\
\hline DM DX 6-10 yrs & 1.434 & 0.668 & 3.080 & 0.3550 \\
\hline$D M D X \geq 11$ yrs & 0.645 & 0.336 & 1.238 & 0.1876 \\
\hline \multicolumn{5}{|l|}{ Final Model } \\
\hline $\mathrm{DM} D \mathrm{DX} \geq \mathrm{II}$ yrs & 0.551 & 0.315 & 0.965 & 0.0371 \\
\hline \multicolumn{5}{|c|}{$\begin{array}{l}\text { 5. Are you willing to have the care manager schedule follow-up on } \\
\text { your treatment progress? }\end{array}$} \\
\hline Male & 1.132 & 0.585 & 2.190 & 0.7133 \\
\hline Age $\leq 50$ & 2.375 & 0.640 & 8.807 & 0.1958 \\
\hline Age $\geq 71$ & 1.036 & 0.549 & 1.954 & 0.9136 \\
\hline Married & 1.694 & 0.880 & 3.262 & 0.1148 \\
\hline College education & 1.070 & 0.559 & 2.048 & 0.8374 \\
\hline Graduate school education & 1.333 & 0.474 & 3.746 & 0.5856 \\
\hline DM DX 6-10 yrs & 1.733 & 0.740 & 4.055 & $0.205 I$ \\
\hline$D M D X \geq 11$ yrs & 0.668 & 0.337 & 1.326 & 0.2492 \\
\hline \multicolumn{5}{|l|}{ Final Model } \\
\hline DM DX 6-10 yrs & 2.159 & 1.023 & 4.555 & 0.0433 \\
\hline
\end{tabular}

6. How confident are you that a care manager can help you keep your diabetes under control?

$\begin{array}{lllll}\text { Male } & 0.869 & 0.460 & 1.640 & 0.6641 \\ \text { Age } \leq 50 & 1.234 & 0.413 & 3.692 & 0.7065 \\ \text { Age } \geq 7 \mathrm{I} & 0.954 & 0.512 & 1.778 & 0.8829 \\ \text { Married } & 1.520 & 0.796 & 2.90 \mathrm{I} & 0.2046 \\ \text { College education } & 1.069 & 0.566 & 2.018 & 0.8367 \\ \text { Graduate school education } & 0.997 & 0.385 & 2.586 & 0.9957 \\ \text { DM DX 6-10 yrs } & 1.193 & 0.538 & 2.647 & 0.6634 \\ \text { DM DX } \geq 1 \mathrm{II} \text { yrs } & 0.566 & 0.287 & 1.116 & 0.1004\end{array}$

Final Model

$\begin{array}{lllll}\text { DM DX } \geq 1 \text { I yrs } & 0.518 & 0.289 & 0.925 & 0.0263\end{array}$

7. How comfortable would you be in discussing your health concerns with the care manager?

\begin{tabular}{lllll} 
Male & 1.672 & $0.81 \mathrm{I}$ & 3.447 & 0.1635 \\
Age $\leq 50$ & 1.457 & 0.379 & 5.606 & 0.5839 \\
Age $\geq 7 \mathrm{I}$ & 0.773 & 0.390 & 1.533 & 0.4614 \\
Married & 1.156 & 0.568 & 2.354 & 0.6897 \\
College education & 1.254 & 0.619 & 2.537 & 0.5298 \\
Graduate school education & 0.908 & 0.328 & 2.518 & 0.8532 \\
DM DX 6-10 yrs & 2.801 & 0.969 & 8.098 & 0.0573 \\
DM DX $\geq 11$ yrs & 0.522 & 0.257 & 1.064 & 0.0735 \\
Final Model & & & & \\
DM DX 6-10 yrs & 4.317 & 1.637 & 11.385 & 0.0031 \\
\hline
\end{tabular}

Abbreviations: $\mathrm{Cl}$, confidence intervals; DM DX, years since first diagnosed with diabetes mellitus.

their "buy-in" to the collaborative care practice. Providers did not differ significantly in their responses on care manager based on age and years of practice, however, this finding may have been limited by the small provider sample size.
Both patients and providers rated themselves as "somewhat" or "extremely comfortable" discussing health concerns or management plans with a care manager. However, providers were more comfortable in expanding the role of a care manager to other chronic diseases; less than $40 \%$ of patients would be willing to see a care manager for management of other chronic illnesses. Lack of patients' previous experience with a care manager may account for this observation.

The majority of patients (74\%) reported confidence in a care manager's ability to help them keep their diabetes under control. The only sub-group who responded differently, as mentioned before, was those diagnosed with diabetes for 11 or more years. There appears to be a tendency for patients who have newly diagnosed diabetes to be more accepting of a new care model. ${ }^{17}$ Nonetheless, this result may indicate readiness on the part of most patients for a different care model.

As to how a care manager should implement various aspects of care delivery, patients expressed a desire for a more individualized approach to their health care needs, as reflected by their preferences for test result notification and education method. This observation is again not surprising; it has been reported that patients do have preferences for different styles of reporting and education. ${ }^{18}$

Just over half of the provider responders reported confidence that a care manager would be helpful in getting patients to be more activated in their diabetes care; the remaining $43 \%$ were "unsure" or "somewhat not confident". This may reflect provider awareness of the difficulty in enhancing self-activation skills. Indeed, most patients (96\%) rated themselves "low" in taking responsibility for their health. Working with patients in developing self-management skills is an identified need based on obtained responses. The association of patients' age to passive role preference and less perceived involvement with decision making had been previously observed, ${ }^{18}$ and is likewise seen among this study's patient responses to self management questions; $90 \%$ of the subjects were over 50 years of age.

The above observation from this study implies the need for a care manager training program that would incorporate motivational interviewing and problem solving skills. Preferences for care management support by patients have been explored and may be helpful in planning this support service. ${ }^{19}$ Interestingly, the majority of responders in this study showed high health literacy level and were functionally able to drive themselves to clinic appointments. These characteristics are potential enablers of patient involvement in a collaborative care model.

The study has its limitations that limit generalizability. Respondents were mostly Caucasian community dwellers 
with type 2 diabetes mellitus, residing in a mid-western section of the United States and results may not be generalized to patients in other geographic locations and minority groups. The questionnaire, although patterned from a previously used survey tool, may lack validity. Finally, characteristics of non-responders were not addressed; it is possible that patients who responded felt differently than those who did not. Study results nonetheless offer a valuable insight into both patients' and providers' perceptions of care managers, which has practice implications. In this study, those with a longer time from disease diagnosis were less willing to see a care manager and may need additional support to engage them in the care model. Training care managers, particularly on motivational interviewing and patient self-management skills, may translate to empowering patients to take charge of their health, which is an essential component of a chronic disease model.

\section{Conclusions}

The results of this self-report survey study provide preliminary evidence that patients and providers are receptive to collaborating with care managers for diabetes management in primary care. Providers may be more comfortable in expanding the role of a care manager to other chronic diseases. Those patients with a longer time since diagnosis of diabetes may be less likely to use a care manager.

\section{Disclosure}

The authors report no conflicts of interest in this work.

\section{References}

1. Unutzer J, Katon W, Callahan CM, et al. Collaborative care management of late-life depression in the primary care setting: a randomized controlled trial. JAMA. 2002;228(22):2836-2845.

2. Hiss RG, Armbruster BA, Gillard ML, et al. Nurse care manager collaboration with community based physicians providing diabetes care: a randomized controlled trial. Diabetes Educ. 2007;33(3):493-502.

3. Von Korff M, Gruman J, Schaefer J, et al. Collaborative management of chronic illness. Ann Intern Med. 1997;127(12):1097-1102.

4. Wagner EH. The role of patient care teams in chronic disease management. BMJ. 2000;320(7234):569-572.
5. DeJesus RS, Chaudhry R, Leutink DJ, et al. Effects of effort to intensify management on blood pressure control among patients with type 2 diabetes mellitus and hypertension: a pilot study. Vasc Health Risk Manag. 2009;5:705-711.

6. Jerant AF, Von Friederichs-Fitzwater MM, Moore M. Patients' perceived barriers to active self-management of chronic conditions. Patient Educ Couns. 2005;57(3):300-307.

7. Rosemann T, Joest K, Korner T, et al. How can the practice nurse be more involved in the care of the chronically ill? The perspectives of GPs patients and practice nurses. BMC Fam Pract. 2006;7:14.

8. Cole SA, Farber NC, Weiner JS, et al. Double-disease management or one care manager for two chronic conditions: pilot feasibility study of nurse telephonic disease management for depression and congestive heart failure. Dis Manag. 2006;9(5):266-276.

9. Hroscikoski MC, Solberg LT, Speri-Hillen JM, et al. Challenges of change: a qualitative study of chronic care model implementation. Ann Fam Med. 2006;4(4):317-326.

10. Noel PH, Frueh BC, Larme AC, et al. Collaborative care needs and preferences of primary care patients with multi morbidity. Health Expect. 2005;8(1):54-63.

11. Centers for Disease Control and Prevention. National diabetes fact sheet: general information on diabetes in the United States, 2005. Atlanta, GA: US Department of Health and Human Services, Centers for Disease Control and Prevention, 2005. Available from: http://www.cdc.gov/ diabetes/pubs/factsheet $05 . h t m$

12. MacLean CD, Susi B, Phifer N, et al. Patient preference for physician discussion and practice of spirituality. J Gen Intern Med. 2003;18(1): $38-43$.

13. Hibbard JH, Stockard J, Mahoney ER, et al. Development of the Patient Activation Measure (PAM): conceptualizing and measuring activation in patients and consumers. Health Services Research. 2004; 39(4 Pt 1):1005-1026.

14. Hibbard H, Mahoney ER, Stockard J, et al. Development and testing of a short form of the patient activation measure. Health Services Research. 2005;40(6 Pt 1):1918-1930.

15. Bennett IM, Chen J, Soroui JS, et al. The contribution of health literacy to disparities in self-rated health status and preventive health behaviors in older adults. Ann Fam Med. 2009;7(3):204-211.

16. Wallace LS, Rogers ES, Roskos SE, et al. Brief report: screening items to identify patients with limited health literacy skills. J Gen Intern Med. 2006;21(8):874-877.

17. Ocklefort E, Shaw RL, Willars J, et al. Education and self-management for people newly diagnosed with type 2 diabetes: a qualitative study of patients' views. Chronic Illn. 2008;4(1):28-37.

18. Rodriguez KL, Appelt CJ, Switzer GE, et al. Veteran's decision making preferences and perceived involvement in care for chronic heart failure. Heart Lung. 2008;37(6):440-448.

19. Sarkar U, Piette JD, Gonzales R, et al. Preferences for self-management support: findings from a survey of diabetes patients in safety-net health systems. Patient Educ Couns. 2008;70(1):102-110.
Patient Preference and Adherence

\section{Publish your work in this journal}

Patient Preference and Adherence is an international, peer-reviewed, open access journal that focusing on the growing importance of patient preference and adherence throughout the therapeutic continuum. Patient satisfaction, acceptability, quality of life, compliance, persistence and their role in developing new therapeutic modalities and compounds to

\section{Dovepress}

optimize clinical outcomes for existing disease states are major areas of interest. This journal has been accepted for indexing on PubMed Central. The manuscript management system is completely online and includes a very quick and fair peer-review system. Visit http://www.dovepress.com/ testimonials.php to read real quotes from published authors. 